\title{
Lessons from Operations Management to Combat the COVID-19 Pandemic
}

\author{
James Randall Patrinley Jr ${ }^{1}$ (D) Sean T. Berkowitz ${ }^{1} \cdot$ Danny Zakria ${ }^{1} \cdot$ Douglas J. Totten ${ }^{1} \cdot$ Mumin Kurtulus $^{2}$. \\ Brian C. Drolet ${ }^{3}$
}

Received: 5 May 2020 / Accepted: 2 June 2020 / Published online: 10 June 2020

(C) Springer Science+Business Media, LLC, part of Springer Nature 2020

In the midst of a global pandemic, lessons from operations management offer crucial insights to healthcare administrators managing the current crisis.

As the world has sought to "flatten the curve" of COVID19 cases to prevent overwhelming the healthcare system, governments have introduced measures such as social distancing and self-isolation to reduce viral spreading and allow healthcare systems to make critical adaptations for testing and triage capacity. Meanwhile, hospitals have found innovative ways to increase their capacity (beds, nurses, doctors) with adequate capabilities to treat COVID-19 patients. The responses range from transforming parking garages and gyms (e.g., Vanderbilt and Yale Medical Centers) into care facilities to the use of Navy hospital ship deployment (in New York city) to building temporary facilities (in Hubei Province in China) to asking for retired medical professionals to return for help in treating COVID-19 patients.

The COVID-19 pandemic has led to significant shortages in personal protective equipment (PPE), ventilators, and potential therapeutic drugs that hinders our ability to combat the pandemic. There are a number of factors that contribute to these shortages. First, many healthcare providers have adopted vendor managed inventory systems that are based on just-in-time-delivery to drive efficiency in the supply

$\overline{\text { J. Randall Patrinley Jr and Sean T. Berkowitz contributed equally to this }}$ work.

This article is part of the Topical Collection on Systems-Level Quality Improvement

James Randall Patrinley, Jr

james.r.patrinely@vanderbilt.edu

1 Vanderbilt University School of Medicine, Nashville, TN, USA

2 Owen Graduate School of Management, Nashville, TN, USA

3 Department of Plastic Surgery, Vanderbilt University Medical Center, Nashville, TN, USA chain. In normal circumstances, this efficiency eliminates excess inventory of supplies and extraneous costs. However, this model has insufficiently met the current surge in demand due to limited inventory in the supply chain. Suppliers who normally produce on stable demand patterns are now struggling to modify production to meet the surge in demand. In the near future, healthcare providers will need to rethink their inventory management strategies, which are geared toward cost efficiency to avoid the shortages of critical supplies.

Another contributing factor to current shortages is the global nature of the medical supply industry. For example, China produces around $50 \%$ of masks used in the world. The lockdown in China to prevent the spread of COVID-19 has led to a disruption in face masks production, which led to significant shortages of masks throughout the world [1]. This is similar to the worldwide shortage of intravenous saline after Hurricane Maria destroyed manufacturing facilities in Puerto Rico [2]. The medical supply industry must rethink the design of global supply chains and develop more effective risk mitigation strategies to relieve and prevent future shortages of essential goods.

Additionally, a significant factor contributing to shortages is the bullwhip effect, a phenomena where a small shock in consumer demand results in significantly larger demand shocks upstream in the supply chain [3]. One of the driving factors of the bullwhip effect is inflated ordering behavior due to limited supply. The ideal allocation method for limited supplies, such as PPEs and ventilators, should be based on relative demand, rather than requested quantities. Presumably, hospitals across the country are placing larger orders based on perceived supply chain issues and imputed future demand. This type of ordering is precisely the mechanism behind the "bullwhip effect" and leads to delays and inefficiencies from manufacturers as well as limited access in areas with the greatest need. Rather, resources should be allocated by demand that is managed from a centralized system. For example, New York hospitals are facing an 
overwhelming surge and should be the first to receive critical supplies, which should be shipped based on immediate, relative needs. To further combat this issue, a practice known as transshipment, where inventory is transferred to from low to high demand regions should be utilized. Recently, Washington state began sending ventilators to New York due to substantial differences in demand. Resource needs should be continuously monitored in each state to ensure supply and demand is optimized. This should be done in a centralized fashion by governments that ensure equitable distribution of limited supplies based on demand rather than anticipated demand.

Finally, when planning initiatives in the current crisis with severely limited resources, accurate modeling is crucial. Discounted cash flow models and considerations of corporate financial structuring are undeniably important for healthcare administrators and may motivate larger discussions during the economic recovery phase of this pandemic. While the nuances of financial models may be less essential for the treatment of disease, the basic tenets of modelling are key lessons that apply to the current situation and may in fact save lives. Namely: 1) a model is only as good as the assumptions underlying its inputs and 2) models are only the start of a discussion. Discussions of "flattening the curve" and the various emerging epidemiologic models for COVID-19 spread are invaluable resources for decision making. However, no model is perfect, and these should be interpreted as the initial points for discussion. Limitations on testing and measurement of COVID-19, international data, and results from randomized clinical trials of varying sample sizes should neither invalidate nor justify overreliance on modeling conclusions and the resulting political or social ramifications. Rather, physicians must be circumspect in evaluation of modeling data and require the appropriate sensitivity analyses, which are commonly required in the medical literature.

Although the current pandemic will be addressed primarily by the healthcare system, concepts from operations management shed light on challenges faced by the healthcare industry. It is clear that some of the operational problems during the COVID-19 pandemic stem from the current system, which is designed for cost efficiency, while managing a pandemic requires flexible systems designed to quickly adapt to a rapidly changing landscape. COVID-19 has taught us that healthcare system must have more flexible backup systems for supply chains to stymie disease spread and adequately equip providers to care for patients in their time of need.

Data availability Not applicable.

\section{Compliance with ethical standards}

Conflicts of interest/Competing interest The authors have no conflicts of interests to disclose.

\section{References}

1. Wang, X., Zhang, X., He, J., Challenges to the system of reserve medical supplies for public health emergencies: reflections on the outbreak of the severe acute respiratory syndrome coronavirus 2 (SARS-CoV-2) epidemic in China. Biosci. Trends. 14(1):3-8, 2020.

2. Abrams, H. R., Normal saline. AMA J. Ethics. 21(8):E699-700, 2019.

3. Lee, H. L., Padmanabhan, V., Whang S., The bullwhip effect in supply chains. Sloan Manag. Rev. 38:93-102, 1997.

Publisher's Note Springer Nature remains neutral with regard to jurisdictional claims in published maps and institutional affiliations. 